\title{
A study on the effect of product quality on behavioral and attitudinal loyalty: A case study of SME companies
}

\author{
Mohammad Amin Sadeghi ${ }^{a^{*}}$, Ali Mollahosseini ${ }^{\mathrm{b}}$ and Mohammadali Forghanic
}

\author{
${ }^{a}$ Student of Executive Master of Business Administration, Department of Management, Shahid Bahonar Univresity, Kerman, Iran \\ ${ }^{b}$ Professor of Management Department, Shahid Bahonar Univresity, Kerman, Iran \\ ${ }^{c}$ Assistant Professor of Management Department, Shahid Bahonar Univresity, Kerman, Iran \\ CH R O I C L E \\ A B S T R A C T
}

Article history:

Received February 252014

Accepted 17 July 2014

Available online

July 182014

Keywords:

Product quality

Behavioral loyalty

Attitudinal loyalty

SME companies

\begin{abstract}
This paper presents an empirical investigation to study the effect of product quality on behavioral and attitudinal loyalty. The study is accomplished among small and medium enterprises (SMEs) located in province of Kerman, Iran. The study designs a questionnaire in Likert scale and distributes it among 180 randomly selected full time employees who work in this region. Cronbach alphas for product quality, behavioral and attitudinal loyalty have been calculated as $0.944,0.865$ and 0.913 , respectively. Using structural equation modeling, the study has confirmed a positive and meaningful relationship between product quality and behavioral $(\beta=0.807 \mathrm{Sig} .=0.000)$ and attitudinal loyalty $(\beta=0.926 \mathrm{Sig} .=0.000)$.
\end{abstract}

(C) 2014 Growing Science Ltd. All rights reserved.

\section{Introduction}

During the past few years, there have been growing competition to provide better quality products and services (Hu et al., 2013). People may switch from one product to another one to get better quality products and services and this makes customer retention much harder than before. There are different studies on learning more about the effects of product quality on various factors. Čater and Čater (2010), for instance, examined how product and relationship quality impact customer commitment along with their combined impact on customer loyalty. They reported that product quality could influence on calculative commitment. In terms of quality, its "social" dimensions such as cooperation and trust had a much bigger effect on commitment than its "technical" dimensions such as knowledge transfers and adaptation. In terms of the "social" side, cooperation and trust positively impact on affective and normative commitment, with trust also positively influencing positive calculative commitment, while on the "technical" side the only significant link was between adaptation and normative commitment. In terms of of commitment, affective commitment positively

*Corresponding author.

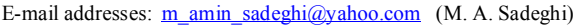


affected attitudinal and behavioral loyalty, while negative calculative commitment positively impacted behavioral loyalty. In terms of indirect effects, product quality also directly positively impacted attitudinal and behavioral loyalty. The results implied that customer loyalty could depend more on affective commitment than on negative calculative commitment and product quality motivation to continue the relationship.

Bennett et al. (2013) shed insights in relationship of brand loyalty from a consumer's perspective, including the notion that the ego-defensive function was an orientation around what others think and could feel. This could build the possibilities for future research into brand loyalty via social network analysis to understand how the thoughts of others influence consumers' loyalty attributes. Lee and

Shin (2014) performed a web-based study to examined how the quality of online product reviews could impact on the participants' acceptance of the reviews as well as their evaluations of the sources. They also tried to understand how such effects change depending on the product kind and the availability of reviewers' photos. For the product specification, an experience good computer game whose quality was difficult to evaluate before firsthand experience and a search good vitamin whose quality could be easily assessed by reading a product description were compared. After gathering overall positive reviews, those exposed to the high-quality versus low-quality reviews examined the product more positively, which in turn, led to a stronger buying intention. However, review quality also had a negative direct impact on the purchase intention for the experience good, with no corresponding impact for the search good. In their survey, high-quality reviews indicated more reviewers' positive evaluations, but they enhanced website evaluation only when the reviewers' photos were present, implying that such visual cues could facilitate systematic message processing.

Behavioral loyalty is one of the most important components of customer loyalty and it is important to learn how various factors influence on this issue. Bandyopadhyay and Martell (2007), for instance, demonstrated that behavioral loyalty could be influenced by attitudinal loyalty across many brands of the toothpaste category.

Romaniuk and Nenycz-Thiel (2013) provided a positive relationship, where those with a higher buying frequency and a higher share of category needs were more likely to provide brand associations. Their findings also demonstrate that share of category requirements was a bigger driver of brand association responses than buying frequency. This finding recommended that the use of competitors had a bigger dampening impact on brand associations than the reinforcement impact of repeated brand buying.

Tanford (2013) studied the impact of tier level on attitudinal and behavioral loyalty of hotel reward program members. She studied the effect of reward tier on attributes established as key loyalty indicators in the hospitality and marketing literature. They reported significant differences between tiers on all measures, with the highest scores for elite members, followed by middle and base/entry level members. Effect size measures disclosed that emotional commitment and program evaluation were core attributes differentiating tier levels.

\section{The proposed study}

This paper presents an empirical investigation to study the effect of product quality on behavioral as well as attitudinal loyalty. The study is accomplished among small and medium enterprises (SMEs) located in province of Kerman, Iran. The sample size of the study is calculated as follows,

$$
n=\frac{N \times z_{\alpha / 2}^{2} \times p \times q}{\varepsilon^{2} \times(N-1)+z_{\alpha / 2}^{2} \times p \times q},
$$


where $N$ is the population size, $p=1-q$ represents the yes/no categories, $z_{\alpha / 2}$ is CDF of normal distribution and finally $\varepsilon$ is the error term. Since we have $p=0.5, z_{\alpha / 2}=1.96$ and $N=300$, the number of sample size is calculated as $n=180$. Fig. 1 demonstrates the structure of the proposed study

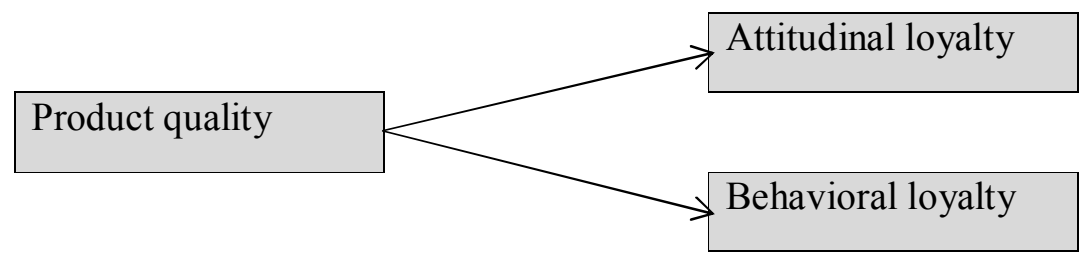

Fig. 1. The proposed study

According to Fig. 1, there are two hypotheses associated with this paper as follows,

1. Product quality influences positively on attitudinal loyalty.

2. Product quality influences positively on behavioral loyalty.

The study designs a questionnaire consists of 9 questions in Likert scale and distributes it among some experts to verify the overall quality of the questionnaire. Cronbach alphas for product quality, behavioral and attitudinal loyalty have been calculated as $0.944,0.865$ and 0.913 , respectively. The study uses structural equation modeling (SEM) to examine the hypotheses of this survey. Table 1 demonstrates the results of some basic statistics associated with SEM implementation.

\section{Table 1}

The summary of some basic statistics

\begin{tabular}{cccccccccc}
\hline Index & P_value & $\chi^{2} /$ df & RMSEA & CFI & NFI & NNFI & GFI & IFI & RMR \\
\hline Acceptable Value & $<0.05$ & $<5$ & $<0.1$ & $>0.9$ & $>0.9$ & $>0.9$ & $>0.9$ & $>0.9$ & $<0.05$ \\
Value & 0.00 & 1.47 & 0.044 & 0.961 & 0.957 & 0.99 & 0.846 & 0.961 & 0.030 \\
\hline
\end{tabular}

As we can observe from the results of Table 1, all statistics are within acceptable level. Table 2 demonstrates the results of our findings on testing two hypotheses of the survey.

\section{Results and conclusion}

In this section, we present details of our findings on testing two hypotheses of the survey.

\section{Table 2}

The summary of testing the hypotheses of the survey

\begin{tabular}{cccccccc}
\hline From & & To & Non-standard $\beta$ & Standard error & Standard $\beta$ & Sig. & Result \\
\hline Product quality & $\rightarrow$ & Attitudinal loyalty & .945 & .030 & .926 & 0.000 & Confirmed \\
Product quality & $\rightarrow$ & Behavioral loyalty & .834 & .047 & .807 & 0.000 & Confirmed \\
\hline
\end{tabular}

Based on the results of Table 2 we may confirm two hypotheses of the survey and conclude that product quality may influence positively on attitudinal as well as behavioral loyalty, positively. The results of this study are consistent with other findings reported by Romaniuk and Nenycz-Thiel (2013), Hu et al. (2008) and Lee and Shin (2014). In other words, an increase on product quality has to increase attitudinal loyalty much more than behavioral loyalty does. 


\section{Acknowledgement}

The authors would like to thank the anonymous referees for constructive comments on earlier version of this paper.

\section{References}

Bandyopadhyay, S., \& Martell, M. (2007). Does attitudinal loyalty influence behavioral loyalty? A theoretical and empirical study. Journal of Retailing and Consumer Services, 14(1), 35-44.

Čater, T., \& Čater, B. (2010). Product and relationship quality influence on customer commitment and loyalty in B2B manufacturing relationships. Industrial Marketing Management, 39(8), 13211333.

Lee, E. J., \& Shin, S. Y. (2014). When do consumers buy online product reviews? Effects of review quality, product type, and reviewer's photo. Computers in Human Behavior, 31, 356-366.

Hu, N., Liu, L., \& Zhang, J. J. (2008). Do online reviews affect product sales? The role of reviewer characteristics and temporal effects. Information Technology and Management, 9(3), 201-214.

Romaniuk, J., \& Nenycz-Thiel, M. (2013). Behavioral brand loyalty and consumer brand associations. Journal of Business Research, 66(1), 67-72.

Russell-Bennett, R., Härtel, C. E., \& Worthington, S. (2013). Exploring a functional approach to attitudinal brand loyalty. Australasian Marketing Journal (AMJ), 21(1), 43-51.

Tanford, S. (2013). The impact of tier level on attitudinal and behavioral loyalty of hotel reward program members. International Journal of Hospitality Management, 34, 285-294. 